\title{
從鈷土礦提棟純鈷之研究
}

\section{II. 鈷液的提净與電解}

\author{
榤元爔 沈邦儒 㛫倩志
}

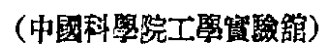

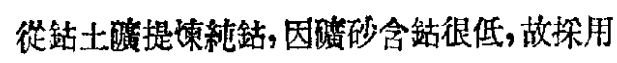

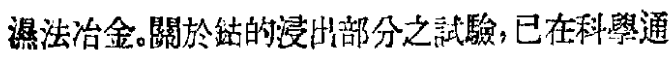

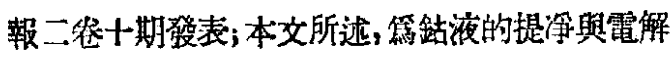
部份之試䮴結果。

\section{鈷液的提净}

(1)鐵的除去: 於鈷浸活液中, 加入 1-2N炭 酸跨溶液(或混濁炭酸鈳)，中和達 $\mathrm{pH} 4-5$, 即有

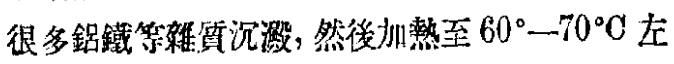

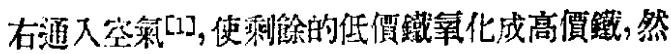

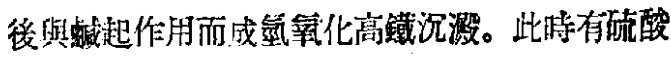
生成，因此須時時加入碳酸缺，使溶液的酸度維持 在 $\mathrm{pH} 4-5$ 之間, 當溶液的酸度無變化時, 即表示 其中的鐵質已全部䭽化。氧化作用的快慢與 $\mathrm{pH}$

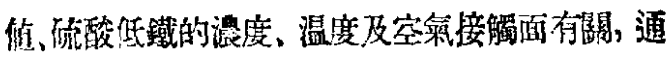
常鐫被氧化的速率的篇每小時每升 0.05 克, 氧化

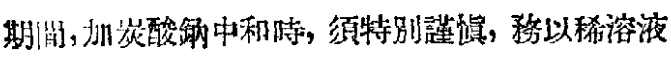
(1N以下)徐徐滴入傜宜, 否則部分鈷液將與局部 䖯险合成碳酸銠沉激而出。雖然溶液的酸度是在 $\mathrm{pH} 5$ 左右, 比碳酸鈷開始沉揤時的酸度 $\mathrm{pH} 6.8$ 略 强, 但已沉溜出來的碳酸鈷就不易再溶解，此項損 失可超過百分之十, 谌至達到百分之二十; 若能謹 慎進行，则損失量可減少到百分之三、四左右。品

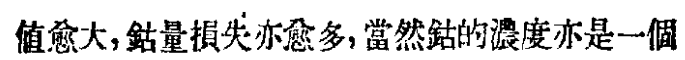
重要因素，以下是我們試䮑所得的一些数掉;

\begin{tabular}{|c|c|c|}
\hline 釿㫾重量 & 100兌 & 200克 \\
\hline 浸出旅念鈷量 & 1830毫克 & 3600 笔克 \\
\hline pH榫 & $5.0-5.5$ & 5.0 \\
\hline
\end{tabular}

践沉激物中念鈷量 79毫克 84毫克
涻的損失率\%

4.4

2.3

（2）銅和鋅的除去：將除去践質後的跍放，通

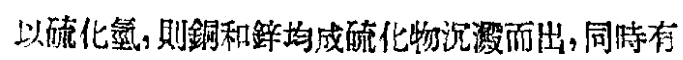

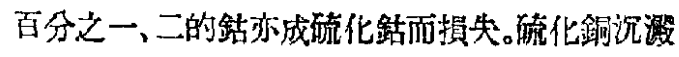
時，能促使硫化鋅易於生成[2]，而達完全程度。以 下是我們訪驗所得的一些關於去鋅的數據。

$\begin{array}{lrr}\text { 溶液中含跍量(每升克数) } & 3.5 & 2.5 \\ \text { 硫化物含鈷量(毫克) } & 35 & 20 \\ \text { 鈷的损失率\% } & 1 & 0.8\end{array}$

演液中含銥量。微量 微量

落遇僅含銅不含鋅的酸砂, 则可在空氣氧化 去鐵前, 在 $\mathrm{pH} 4-5$ 左右時, 加廢鐵屑於鈷溶液 中, 將銅替代而除去之。此项手續較通硫化氢簡便 而殓湾。

(3)和鈷的分開; 唋和銛的化學性質很相 近, 因此很不容是分開。通常用的分離方法是根據

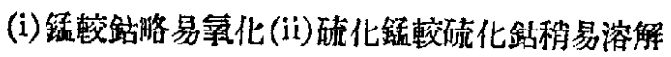
這雨點來區別。

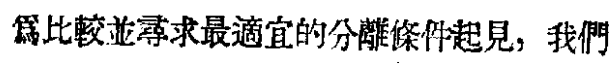
做了以下的試驗:

(i) 在已知銛鋁湿合液中加入漂白粉斌之

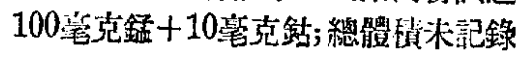

\begin{tabular}{|c|c|c|c|c|}
\hline 試驗號嫩 & $\begin{array}{c}\text { 确酸惯度 } \\
(\mathrm{N})\end{array}$ & 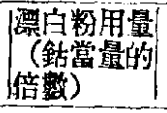 & 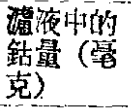 & 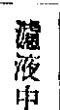 \\
\hline E. 1 & 0.4 & 0.75 & 2.4 & 的 \\
\hline E. 2 & 0.4 & 1.00 & 5.4 & 䭪 \\
\hline E. 3 & 0.4 & 1.25 & 6.0 & 来 \\
\hline E. 4 & 0.4 & 1,50 & 6.8 & 定 \\
\hline
\end{tabular}

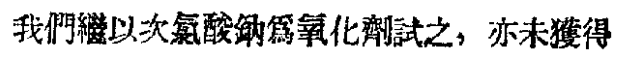


良好結果。

(ii)以䣼化跒處理之

100毫克籍 +10 毫克鈷; 總體積未記銭

\begin{tabular}{|c|c|c|c|c|}
\hline 訊驗踏数 & 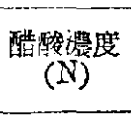 & 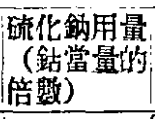 & $\begin{array}{l}\text { 泾澱中的 } \\
\text { 鍷量（毫 } \\
\text { 克） }\end{array}$ & $\begin{array}{l}\text { 治 } \\
\text { 激 } \\
\text { 中 }\end{array}$ \\
\hline E. 5 & 0.4 & 0.9 & 2.0 & 籍 \\
\hline F. 6 & 0.4 & 2.8 & 8.0 & 霜 \\
\hline E. 7 & 0.4 & 7.0 & 9.8 & $\begin{array}{l}\text { 测 } \\
\text { 定 }\end{array}$ \\
\hline
\end{tabular}

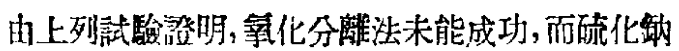

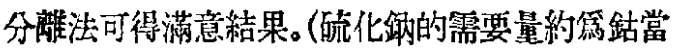

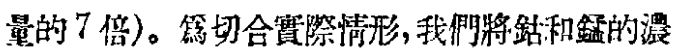

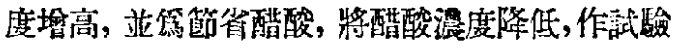
如下:

1400 完克鎦+160毫克鎮;

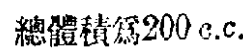

\begin{tabular}{|c|c|c|c|c|}
\hline 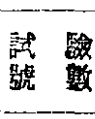 & $\begin{array}{l}\text { 酳酸濃 } \\
\text { 度 }(\mathrm{N})\end{array}$ & 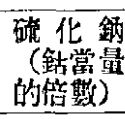 & 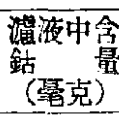 & 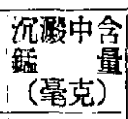 \\
\hline E. 8 & 0.1 & 1 & 1.5 & 0.72 \\
\hline E. 9 & 0.1 & 2 & 0,07 & 0,76 \\
\hline E. 10 & 0.1 & 4 & 0,00 & 1.11 \\
\hline E. 11 & 0.1 & 8 & 0.00 & 3.15 \\
\hline
\end{tabular}

由上結果, 可知當鋯的㶎度提高洔, 只要䏐二 倍鉆賞量的硫化测, 在 $0.1 \mathrm{~N}$ 醁酸的溶液中, 即可

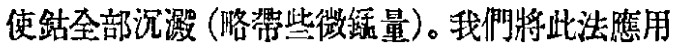
於鈷浸出液作試驗如下:

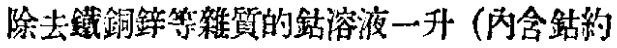
3 克䠄約 16 克) 加入 18 毫升冰醁酸 (99\%) 熱至

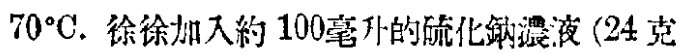

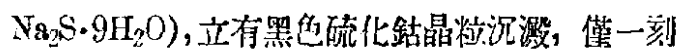

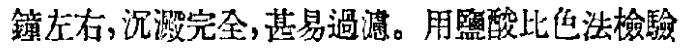

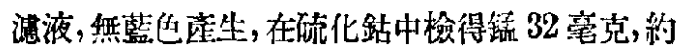
䉆鈷量的 1\%。

(iii)以電解法處理之

硫化解法踓相當成功, 但成本較贵、因此又選 電解法作試駽如下:

陰極: 一不銗龬陽極: 一鉊 网極距離約 3.8厘米 平均電流密度: 4安培/平方 分米 $\mathrm{pH}: 1.7 \longrightarrow 1$ (用碳酸䍇中和酸電解液以 維持酸度)

總容積: 100 毫仆 温度: 室温 $\left(22^{\circ} \mathrm{C}\right)$
時間: 一2.5小㭙

\begin{tabular}{|c|c|c|c|c|}
\hline 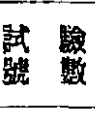 & $\begin{array}{c}\text { 靁解液 } \\
\text { 內钴量 } \\
\text { (克) } \\
\text { 党 }\end{array}$ & 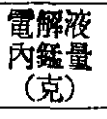 & $\begin{array}{c}\text { 金麗鈷的 } \\
\text { 軍 量 } \\
\text { (毫克) }\end{array}$ & 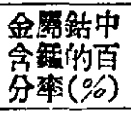 \\
\hline F. 12 & 1 & 0.5 & 990 & 0.053 \\
\hline E. 13 & 1 & 1 & 967 & 0.100 \\
\hline E. 14 & 1 & 2 & 936 & 0.087 \\
\hline E. 15 & 1 & 4 & 792 & 0.155 \\
\hline E. 16 & 1 & 6 & 720 & 0.255 \\
\hline
\end{tabular}

由上結果，得知鈷亦可從大量鉬中以電解法 分離出來，在原溶液中，含舒成份較高者，在金屈

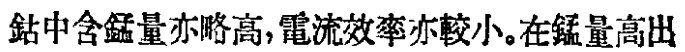
鈷量六倍時, 所得金屬鈷中的含檤量約第 $0.26 \%$ 。

我們繼將鈷浸出液作試駿如下:

除去鐵銅鋅等雜質的鉆溶液800毫升(含涻 10

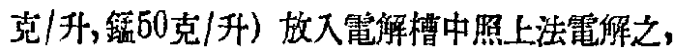
惟温度较高, 緛常維持在 $70^{\circ} \mathrm{O}$ 到 $80^{\circ} \mathrm{C}$ 之間,電流 染度較小，篇 2 安培/本方分米, 同時在電解期間 時時加入新電解液及放出酸電解液, 使溶液的容 積和 $\mathrm{pH}$ 值保持不變,流出的酸電解液，以碳酸䣄 中和後作䉆新電解液供循罢之用, 直至溶液內含 站量相堂稀少篇止，並於中途更換陰極三次，以筧 察钚在電解鈷各階段中的含量變化的情形，其結 果如下:

\begin{tabular}{|c|c|c|c|}
\hline 僣 & I & II & III \\
\hline 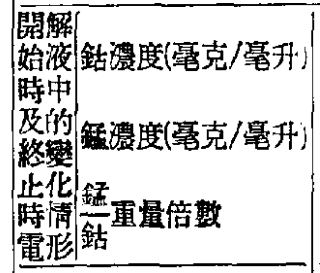 & $\begin{array}{c}10 \rightarrow 5.1 \\
50 \rightarrow 58 \\
5 \rightarrow 11\end{array}$ & $\begin{array}{l}5.1 \rightarrow 3.2 \\
58 \rightarrow 106 \\
11 \rightarrow 33\end{array}$ & $\left\{\begin{array}{l}3.2 \rightarrow 0.9 \\
106 \rightarrow 186 \\
33 \rightarrow 151\end{array}\right.$ \\
\hline 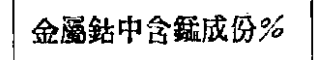 & 1.10 & 1.45 & 1.75 \\
\hline 陰㮴 & 很光 & 色黑, 面 & 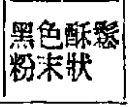 \\
\hline
\end{tabular}

由上結果，得知當鎾量第鈷量的 33 倍到 151 倍時, 所得鈷中的含﨨量篇 $1.75 \%$ 较硫化鸰法略

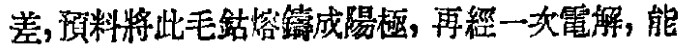
得純站的可能性很大。

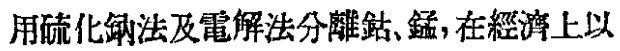
何法較徒, 須侯小型提鈷工場成立之後，進行較 大規模試驗方可比較决定。

(4)製成氧化站或硫酸鈷: 
（a)笠氧化鈷: 將硫化站在 $900^{\circ} \mathrm{C}-1000^{\circ} \mathrm{C}$ 左 右灼燒 5-6 小㭙, 則幾全被氧化而成深藍色的氧 化鈷。從下列試驗数㨜，可知本炏試驗 中所得 的硫化跕的分子式篇 $\mathrm{CaS}_{2}$, 氧化鈷的分子式篇 $\mathrm{Co}_{2} \mathrm{O}_{3}$;

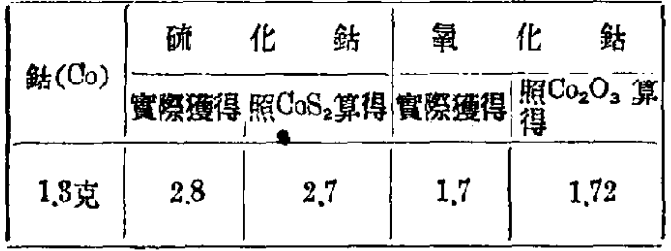

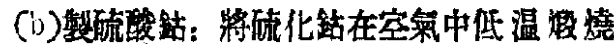
之，即徐徐氧化而成䂭酸鈷，但温度若昇到 $620^{\circ} \mathrm{C}$ 洔，硫酸鈷將開始分解而成莘化鈷和三氧化硫， 硫酸低鐵在 $600^{\circ}$ 及 $650^{\circ} \mathrm{C}$ 間茎部分解 成氧化

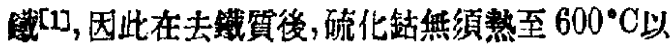
.上，以防活酸鈷分解成氧化鈷，關於榩燒需要的温 度,我們作了以下的試驗:

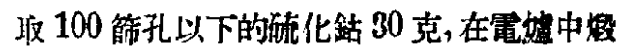

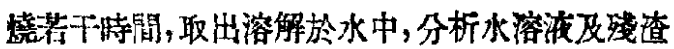
中的含跕量，以检定硫酸鈷的生成率。

\begin{tabular}{|c|c|c|c|}
\hline 試融 & $\begin{array}{l}\text { 閶给温度 } \\
\left({ }^{\circ} \mathrm{C}\right) \\
(2 小 \text { 㭙) }\end{array}$ & $\begin{array}{c}\text { 終了温度 } \\
\left({ }^{\circ} \mathrm{C}\right) \\
(6 \text { 小時 })\end{array}$ & 硫酸鈷的生成亭\% \\
\hline$F_{1}$ & 320 & 320 & 73.0(籿紅色) \\
\hline $\mathrm{F}_{2}$ & 400 & 400 & 96.8(䊀紅色) \\
\hline $\mathrm{F}_{3}$ & 400 & 520 & 98.8 (粉紅色) \\
\hline $\mathrm{F}_{4}$ & 400 & 500 & $97.5($ 籵紅色) \\
\hline $\mathrm{F}_{\mathrm{s}}$ & 520 & 520 & $97 . i$ (粉紅色) \\
\hline $\mathrm{F}_{6}$ & 400 & 600 & 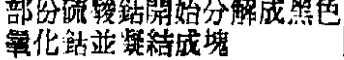 \\
\hline
\end{tabular}

由上澄明，煆燒最適宜的温度是 $400-550^{\circ} \mathrm{C}$,

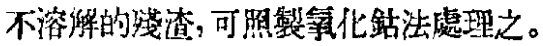

另一次取去鐵完全的硫化鈷樣品 1 克作 $F_{7}$ 、

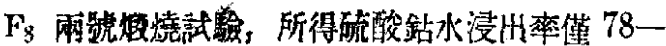
79\%炇燒物呈黑褐色，與上婊試驗結果相差太透。

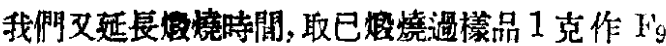
陚駿, 結果水浸出率增至 $83.6 \%$, 仍較上表結果䉆

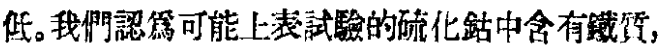
起接解作用 ${ }^{[4]}$ 。故在硫化鈷中加入硫酸低鐵少許

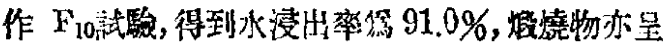

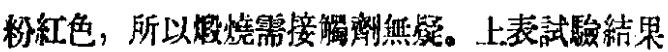
可能因去鐵卡完全所致。

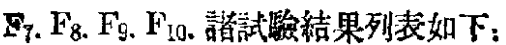

\begin{tabular}{|c|c|c|c|c|}
\hline \multirow{2}{*}{ 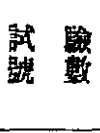 } & \multirow{2}{*}{ 温度 ${ }^{\circ} \mathrm{C}$} & \multirow{2}{*}{$\begin{array}{l}\text { 時䦙 } \\
\text { (小時) }\end{array}$} & \multicolumn{2}{|c|}{ 鉆的浸出霖 } \\
\hline & & & 水惯比率\% & $\begin{array}{c}10 \% \mathrm{H}_{2} \mathrm{SO}_{4} \\
\text { 贯出事\% }\end{array}$ \\
\hline \multirow{2}{*}{$\mathrm{F}_{7}$} & 400 & 5 & & \\
\hline & 470 & 2 & 79.3 & 20.4 \\
\hline \multirow{3}{*}{$F_{8}$} & 300 & 4.5 & & \\
\hline & 410 & 3 & & \\
\hline & 475 & 2.5 & 78.4 & 21.6 \\
\hline \multirow{3}{*}{$\mathrm{F}_{0}$} & 300 & 4.5 & & \\
\hline & 410 & 3 & & \\
\hline & 475 & 2.5 & 83.6 & 16.4 \\
\hline \multirow{3}{*}{$F_{10}$} & $\mathbf{3 0 0}$ & 4,5 & & \\
\hline & 410 & 3 & & \\
\hline & 475 & 2.5 & 91.0 & 9.0 \\
\hline
\end{tabular}

\section{的的蜻}

(1)鈷液的高度提净: 將层燒成的硫酸䟯用湴 鋯水浸出(或将氧化鉆溶於監酸中)，使成至少每 开含10 克鈷的瀑硫酸鉆溶液，加純碳酸詅到靠近

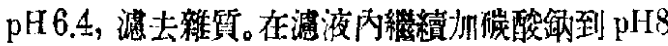
左右，大部硫酸鈷呈玫瑰紅色沉澱而出。過湛後以

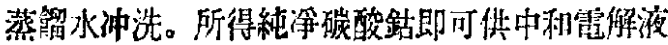
內酸份之用。满腹及洗液再加碳酸缺到 $\mathrm{pH}$ 9以收 回剩狳的鈷，此碳酸鈷可用來代替一部份碳酸缸 以中和砕酸跕溶液沉澱碳酸鈷, 所取 $\mathrm{pH}$ 值的範

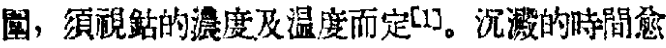
長窟完善, 但至少須在 24 小㭙以上。沉澱的碳酸鉆 以中間部份 $(\mathrm{pH}$ 6.4-7.2間所成沉潵) 最第純浮。

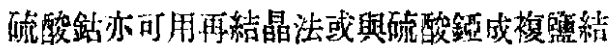
晶法提純之。

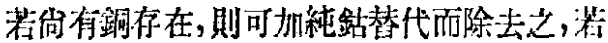

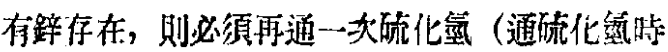
的 $\mathrm{pH}$ 倠切不可大於 6 )。鋅是電许持最有害的雜 筫, 每升鉆雪解液中，如含鋅超過 10 毫克(3), 就不 能得到表面度好的金盛鈷了。

(2)電解製純鈷: 將純碳酸鈷溶解於純硫酸,

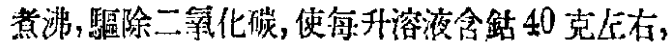
其 $\mathrm{pH}$ 做在 $1.7 \pm 0.2$ 之間, 即成電解液。我們所肋

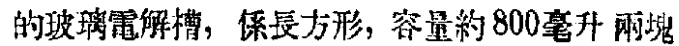

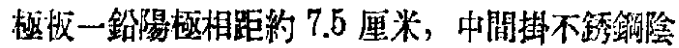
塊。加入電解液約 600 毫升後, 浸浔部分的陰枢, 间 積約篇 75 平方厘米。加熱至 $60^{\circ} \mathrm{C}$, 以 2.7 安培/平 


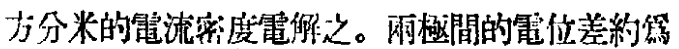
3.2 伏特。在此期間, 應時時加入新電解液及放 壮酸電解液, 使溶液的深度、浱度及 $\mathrm{pH}$ 值保持不 變。流出的酸電解液, 以純碳酸鈷中和瀑過後, 作 骂新電解液倛循環之用。電解液中有少量塗質存 在, 非但無害, 反可使鈷不在陽極析出。通常無絰 存在時, 在陽極的雑質中往往有過氧化鈷 $\left(\mathrm{COO}_{2}\right)$ (3) 生成; 如有少量钙存在, 鈷的損失可減少到 $2 \%$ 任右, 可能鈷首先在陽極氧化成過氧化鈷, 然後再 被 $\mathrm{Mn}^{++}$還原成 $\mathrm{Co}^{+++}$。

$$
\mathrm{CoO}_{2}+\mathrm{Mn}^{++}=\mathrm{MnO}_{2}+\mathrm{Ca}^{++}
$$

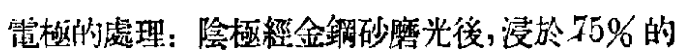
硫酸(此重 1.42) 中約一小時, 然後以蒸餙水冲洗

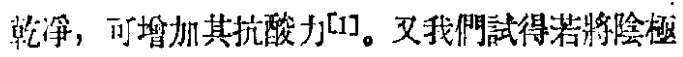
柾 $10 \%$ 水玻璃溶液處理後, 䉓解所得銛校易取 下。

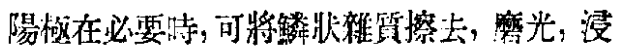

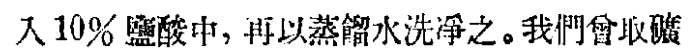
砂 40 斤, 梁上述各步㵵處理後, 作電解陚䮑, 結果 谌徒, 電流效率約第 $66 \%$ 。笔解侍, 鉆先䤼鍍仕,

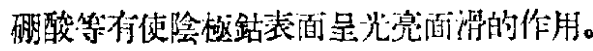

電 解 試 颐

\begin{tabular}{|c|c|c|c|}
\hline 期 & 1951年 4月28日 & $\begin{array}{l}1951 \text { 年5月 } \\
10 \text { 日 }\end{array}$ & $\begin{array}{l}1951 \text { 年 } \\
7 \text { 月 } 15\end{array}$ \\
\hline $\mathrm{Co}$ (克/升) & 40 & 40 & 未 \\
\hline $\begin{array}{l}\mathrm{H}_{3} \mathrm{IOO}_{3} \\
\text { (克/升) }\end{array}$ & - & 30 & 記 \\
\hline $\operatorname{SaF}$ (克/升) & - & 5 & \\
\hline 本沟pHI 直 & $1.6 \pm 0.1$ & $1.7 \pm 0.1$ & 鐵 \\
\hline $\begin{array}{l}\text { 平沟電流 (实 } \\
\text { 培) }\end{array}$ & $1.8 \pm 0.2$ & $1.75 \pm 0.5$ & \\
\hline $\begin{array}{l}\text { 平沟電侣厓 } \\
\text { (快特) }\end{array}$ & $3.2 \pm 0.1$ & $3.2 \pm 0.1$ & \\
\hline 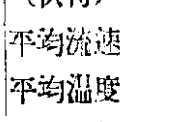 & 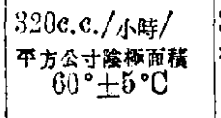 & 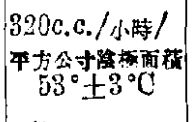 & \\
\hline 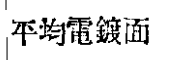 & $70 \pm 54$ 方每米 & 70 土地方鹳米 & \\
\hline 時間(小時) & 25 & 28 & \\
\hline 純鉆(克) & 33 & 33 & \\
\hline 電流效梀 $(o)$, & 66 & 66 & \\
\hline $\begin{array}{l}\text { 每隹厅鈷朋電 } \\
\text { 没数 }\end{array}$ & 4,4 & 4.8 & \\
\hline 婊面情据 & 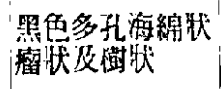 & $\begin{array}{l}\text { 平滑光亮良 } \\
\text { 好 }\end{array}$ & \\
\hline
\end{tabular}

純 鈷分析

\begin{tabular}{|c|c|c|c|c|}
\hline 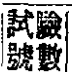 & \multicolumn{3}{|c|}{ 甲 } & \multirow{3}{*}{$\begin{array}{c}\text { 乙 } \\
1951 \text { 年 } 7 \\
\text { 月15日 }\end{array}$} \\
\hline 日 & \multirow{2}{*}{$\begin{array}{l}\text { 1951年 } 4 \\
\text { 月28日 }\end{array}$} & \multicolumn{2}{|c|}{1951 年5 月10日 } & \\
\hline 期 & & 電解液 & 陰楆鈷 & \\
\hline $\mathrm{Ni}$ & - & $5.2 \%$ & $1.35 \%$ & $1.13 \%$ \\
\hline $\mathrm{S}$ & $0,001 \%$ & - & $0.004 \%$ & $0.001 \%$ \\
\hline $\mathrm{Pb}$ & - & - & $0.02 \%$ & $0.080 \%$ \\
\hline $\mathbf{M n}_{\mathbf{n}}$ & 一 & $11.4 \%$ & $0.007 \%$ & $0.007 \%$ \\
\hline $\mathrm{Fe}$ & $0.036 \%$ & - & $0.041 \%$ & $0.077 \%$ \\
\hline $\mathrm{Zn}$ & $<0.01 \%$ & - & $<0.01 \%$ & $0.02 \%$ \\
\hline $\mathrm{Ou}$ & $0.006 \%$ & - & $0,02 \%$ & $0.023 \%$ \\
\hline $\mathrm{Ca}$ & - & - & - & $0.053 \%$ \\
\hline
\end{tabular}

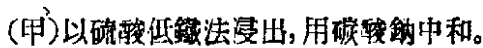

（乙）以二氧化硫法浸出，用碳酸釬山和，雪解掅况 與5月10日同。

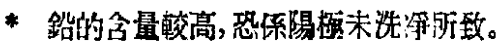

\section{總結}

(1)空氣氧化法去鐵封, 在 4 至 5 的 pH 俻下 進行,帶走的銛較少。

(2) 在 $0.1 \mathrm{~N}$ 醌酸溶液中，加雨倍於鈷當量的

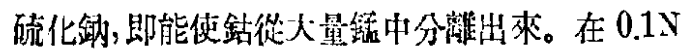

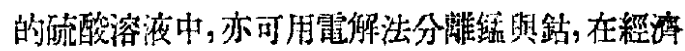
上以何法較佳, 須從較大規慔的試䐘决定。

(3) 在 $400-550^{\circ} \mathrm{C}$. 間，硫化鈷能大部 $(95 \%$ 以上)煆燒成䃊酸涻。

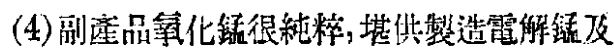
乾電池之用。

(5) 在 $\mathrm{pH} 1.7 \pm 0.2$ 及每升含銛 30 克到 40 克 的硫酸涻溶液中進行電獬，涻的純度能涬 $99.9 \%$ （包括少量鎳在內）

\section{勢考文獻}

[1] F. K. Shelion; Ruch E. Chureitwonl; J. C. Siahl and C. W. Davis; Transactions of the Amer. Electrochemical Society Vol. 91, 1947. p. 115

[2] Kolthoff and Sandell: Text-book of Quantitative Inorganic Analysis. p. 113.

[3] Ruth E. Churchword; F. K. Shelion and ( $x$. P. Knickerbond: Transactions of the Amer. Electrochemical Socrety Vol. 85, 1944, p. 193.

[4] Liddell Handbook of Nonferrous Metallurgy. p. 279 . 
由鈷土䃥提枯綀鈷的程序

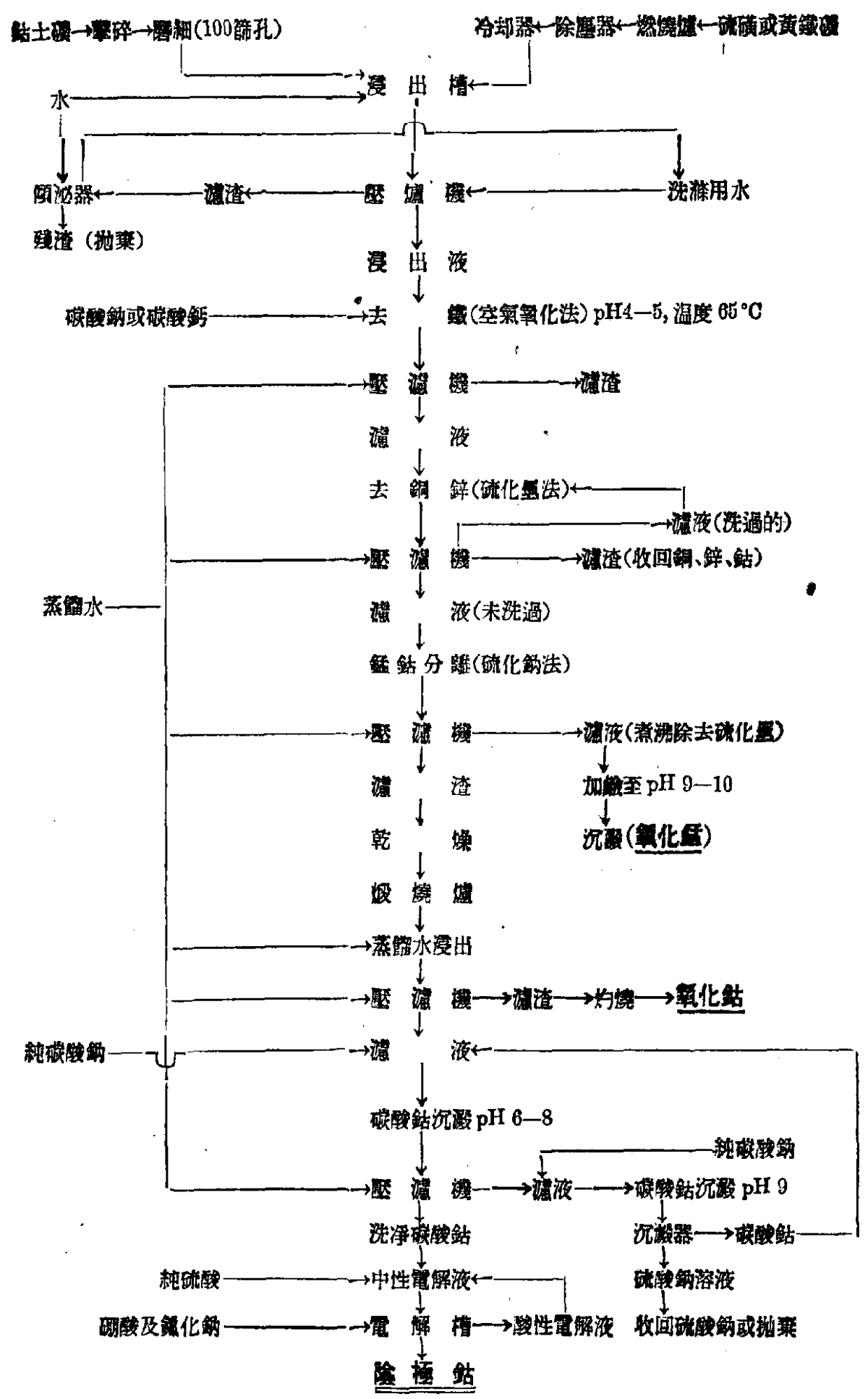

